\title{
ANALISIS PERTUMBUHAN DAN HASIL TANAMAN JABON (Anthocephallus cadamba)
}

\author{
Growth and Yield Analysis of Jabon Plantation (Anthocephallus cadamba)
}

\author{
Wahyudi ${ }^{\square}$
}

Jurusan Kehutanan, Faperta, Universitas Palangka Raya, Palangka Raya, Kalimantan Tengah

\begin{abstract}
Anthocephallus cadamba was a native species and one of some commercial trees which had a good prospect to develop on the low production forest. This research was aimed to analyze growth and yield of A. cadamba plantation, including the living trees percentage, productivity, economic cutting cycle, and its profit. Parameter of data analysis used trees diameter, high and volume, mean annual increment, polynomial equation modelling and financial analysis i.e. net present value (NPV), and benefit cost ratio (BCR). The research had been conducted at research plots of $A$. cadamba in sub District of Mandau Talawang, Central Kalimantan Province since 1998 to 2010. Soil type in the site was ultisol former shifting cultivation and scrubs. The result of this research showed that living trees precentage at 12 years old was $57.7 \%$. Mean annual increment and its density were $19.05 \mathrm{~m}^{3} \mathrm{ha}^{-1}$ and 641 tree ha-1 respectively. Equation modelling of jabon plantation was $y=4.7814+3.6028 x-0.185 x^{2} \quad\left(R^{2}=63.34 \%\right)$. In the bank rate of $9 \%$ year ${ }^{-1}$, the economic cutting cycle of this plantation was 13 years with net present value was IDR 72,79 million per ha. If the bank rate of $6 \%$ and $12 \%$ per year, then net present value at the 13 years were IDR 108.52 and IDR 48.56 million ha-1 respectively. The A. cadamba was suitable to timber estate and to increase the productivity of former shifting cultivation, scrub, and low potential forest areas.
\end{abstract}

Key words: growth and yield, mean annual increment, Anthocephallus cadamba, economic cutting cycle

\section{PENDAHULUAN}

Laju kerusakan hutan sebesar 1,8 juta ha setiap tahun (1985-1997) dan meningkat menjadi 2,84 juta ha setiap tahun pada tahun 1997-2000 (Balitbanghut, 2008). Sejalan dengan penurunan luas kawasan hutan serta tingginya laju kerusakann hutan, kemampuan produksi kayu bulat nasional juga mengalami penurunan. Pada tahun 1992 produksi kayu bulat nasional sebesar 26,05 juta $^{3}$ thn $^{-1}$, namun kemudian menurun tajam pada tahun

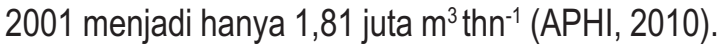
Sejak saat itu produksi kayu bulat nasional tidak pernah mencapai angka di atas 10 juta $\mathrm{m}^{3} \mathrm{thn}^{-1}$.

Untuk meningkatkan kembali produksi kayu bulat nasional dapat ditempuh melalui pembangunan hutan tanaman, baik yang dilakukan oleh perusahaan dalam bentuk izin Usaha Pemanfaatan

Diterima: 2 September 2011; Disetujui: 10 Desember 2011

$\square$ Penulis korespondensi (corresponding author): isanautama@yahoo.com
Hasil Hutan Kayu-Hutan Tanaman (IUPHHK-HT) maupun dilakukan oleh masyarakat dalam bentuk Hutan Tanaman Rakyat (HTR), Hutan Rakyat dan lain-lain. Pemilihan jenis tanaman merupakan komponen penting untuk menunjang keberhasilan program hutan tanaman. Jenis-jenis intoleran yang dapat tumbuh di daerah terbuka merupakan pilihan yang tepat untuk dikembangkan dalam kawasan hutan yang telah terdegradasi.

Salah satu jenis intoleran dan komersial lokal (native species) yang dapat dikembangkan dalam hutan tanaman adalah jabon ( $A$. cadamba). Menurut Dephut (1989) kayu jabon mudah dikerjakan, lunak dan ringan, berwarna putih krim sampai sawo kemerah-merahan, bersinar dan sedikit berpori dengan berat jenis rata-rata 0,42 atau berkisar antara 0,29 sampai 0,56 . Memiliki kelas kuat III (sedang) dan kelas awet IV sampai V.

Di India, Pilipina dan Malaysia jabon banyak ditanam untuk industri vinir dan kayu lapis sedangkan di Jawa kayu jabon digunakan untuk pembuatan peti dan korek api. Menurut Ditjenhut (1980) kayu jabon 
baik digunakan untuk pembuatan peti, papan tipis, korek api, pensil, vinir dan kayu lapis serta untuk pulp dan kertas.

Dalam rangka mendukung pengembangan hutan tanaman kelas perusahaan kayu jabon, maka diperlukan informasi tentang analisis pertumbuhan dan hasil serta kelayakan finansial terhadap tanaman ini. Oleh karena itu penelitian tentang tanaman jabon ini sangat diperlukan.

Penelitian ini bertujuan untuk mengetahui prosen hidup, produktifitas, siklus tebang ekonomi dan keuntungan finansial dari tanaman jabon. Informasi ini diharapkan dapat membantu para pihak (stakeholder) dalam membangun hutan tanaman menggunakan jenis jabon.

\section{BAHAN DAN METODE}

Penelitian dilakukan di Kecamatan Mandau Talawang, Kabupaten Kapuas, Provinsi Kalimantan Tengah. Pengambilan data dilakukan pada saat tanaman berumur $0,2,4,8$ dan 12 tahun sejak penanaman tahun 1998 sampai tahun 2010 .

\section{Prosedur Penelitian}

1. Plot penelitian tanaman jabon ditanam tahun 1999 dengan jarak tanam $3 \mathrm{~m} \times 3 \mathrm{~m}$. Pada awalnya, lokasi plot penelitian merupakan semak belukar, hutan potensi rendah serta bekas perladangan berpindah. Jenis tanah Ultisol berwarna kuning kemerahan dengan tekstur lempung liat berpasir (sandy clay loam). Tebal lapisan humus berkisar 0,5-21,0 cm.

2. Plot penelitian ditentukan seluas 1 ha yang diambil secara acak.

3. Perawatan tanaman jabon dilakukan setiap tahun pada 3 tahun pertama dan setiap 3 tahun pada periode berikutnya melalui pemulsaan dan pembersihan dari gulma dan tumbuhan pengganggu.

4. Pengambilan data dilakukan terhadap diameter (dbh) dan tinggi bebas cabang pada tahun 1998, 2000, 2002, 2006, 2010.

\section{Analisis Data}

1. Rata-rata data ditentukan menggunakan rumus:

$\mu=1 / n \cdot \Sigma X_{i}$
Dimana :

$X_{i}=$ jumlah data dari $X_{1}$ sampai $X_{n}$

$\mu=$ nilai tengah atau rata-rata

$\mathrm{n}$ = banyak data

2. Persentase hidup tanaman ditentukan menggunakan pendekatan:

Persen hidup $=\frac{\text { tanaman hidup }}{\sum \text { tanaman yang ditanam }} \times 100 \%$

3. Volume pohon dihitung melalui:

$V=0,25 \cdot \Pi \cdot D^{2} \cdot h \cdot 0,7$

dimana

$\pi=3,14$

$\mathrm{D}=$ diameter $\mathrm{dbh}$

$\mathrm{h}=$ tinggi pohon.

4. Pola pertumbuhan tanaman jabon dibentuk melalui persamaan polinomial (Brown, 1997; Burkhart, 2003):

$y=c_{1}+c_{2} x+c_{3} x^{2}$

dimana:

y : diameter akhir rata-rata

$\mathrm{x}$ : waktu dalam tahun

$\mathrm{C}_{1}, \mathrm{C}_{2}, \mathrm{C}_{3}:$ konstanta

5. Analisa Finansial

Perhitungan Net Present Value (NPV), Benefit Cost Ratio (BCR dan Internal Rate of Return (IRR) ditentukan melalui persamaan (Nair, 1993):

$$
\begin{aligned}
& N P V=\sum_{t=0} \frac{r B_{i}}{(1+i)^{t}}-\sum \sum_{t=0 \quad(1+i)^{t}} \frac{r C_{i}}{(1+i)^{t}}: \sum_{t=0} \frac{r C_{i}}{(1+i)^{t}} \\
& B C R=\sum_{t=0} \frac{r B_{i}}{(1=0}
\end{aligned}
$$

dimana:

$\mathrm{B}_{\mathrm{t}} \quad$ : penerimaan (benefit) tahun ke-t

$\mathrm{C}_{t}$ : pengeluaran (cost) tahun ke-t

$r, t$ dan i : siklus tebang, waktu (tahun) dan suku bunga sebesar $9 \%$

Proyek dinilai layak bila NPV $>0, B C R 1$ dan IRR> suku bunga

Analisis sensitifitas dilakukan untuk mengetahui output proyek jika terdapat suatu penyimpangan atau perubahan dalam dasar-dasar perhitungan biaya (cost) maupun manfaat (benefit) (Gray et al., 1999). Dalam penelitian ini analisis sensitifitas dilakukan terhadap beberapa tingkat suku bunga, yaitu 6 dan $12 \%$. 
Tabel 1. Rekapitulasi riap diameter dan tinggi bebas cabang tanaman jabon

\begin{tabular}{cccccc}
\hline Tahun & Umur (thn) & Diameter $(\mathrm{cm})$ & $\begin{array}{c}\text { MAl diameter }(\mathrm{cm} \\
\left.\text { thn }^{-1}\right)\end{array}$ & $\begin{array}{c}\text { Tinggi bebas } \\
\text { cabang }(\mathrm{m})\end{array}$ & MAI Tbc $\left(\mathrm{m} \mathrm{thn}^{-1}\right)$ \\
\hline 1998 & 0 & 3,91 & 0,00 & 0,94 & 0,00 \\
2000 & 2 & 12,25 & 6,13 & 3,74 & 1,87 \\
2002 & 4 & 16,98 & 4,25 & 6,46 & 1,62 \\
2006 & 8 & 20,40 & 2,55 & 10,56 & 1,32 \\
2010 & 12 & 21,88 & 1,82 & 14,57 & 1,21 \\
\hline
\end{tabular}

\section{HASIL DAN PEMBAHASAN}

Tanaman jabon pada umur 12 tahun mempunyai riap diameter tahunan rata-rata (MAI diameter) sebesar 1,82 $\mathrm{cm} \mathrm{thn}^{-1}$ dan riap tinggi bebas cabang tahunan rata-rata (MAl tinggi bc) sebesar 1,21 m $t^{t h n}{ }^{-1}$. Namun demikian sebaran data diameter dan tinggi tanaman cukup tinggi karena banyak tanaman yang telah mencapai diameter $34,6 \mathrm{~cm}$ dan tinggi 21 $\mathrm{m}$, namun ada pula yang baru mencapai diameter $9,8 \mathrm{~cm}$ dan tinggi $7,5 \mathrm{~m}$ pada umur 12 tahun. Keragaman data $(\delta)$ diameter dan tinggi masingmasing 0,58 dan 0,35 . Hasil pengukuran diamater dan tinggi bebas cabang tanaman jabon pada plot penelitian dapat dilihat pada Tabel 1 .

Sutisna dan Ruchaemi (1995) mencatat MAI diameter dan tinggi sebesar $3,11 \mathrm{~cm}^{\text {thn }}{ }^{-1}$ dan 1,35 $m$ thn $^{-1}$ pada umur 5 tahun. Berdasarkan Tabel 1 , tanaman jabon mempunyai MAI diameter sebesar 6,$13 ; 4,25 ; 2,55$ dan $1,82 \mathrm{~cm}$ thn $^{-1}$ serta MAl tinggi bebas cabang sebesar 1,$87 ; 1,62 ; 1,32$ dan 1,21 $\mathrm{m}$ thn ${ }^{-1}$ masing-masing pada umur 2, 4, 8 dan 12 tahun. Dengan demikian pertumbuhan rata-rata tanaman jabon membentuk grafik parabola terbalik, yaitu lambat pada awal pertumbuhan, kemudian cepat dan mengalami perlambatan kembali. Grafik pertumbuhan, MAI dan CAI tanaman jabon dalam dilihat pada Gambar 1.

Persentase hidup tanaman jabon pada umur 12 tahun sebesar $57,7 \%$, dengan demikian kerapatan tanaman pada umur 12 tahun mencapai 641 pohon ha-1 (Jumlah tanaman jabon pada awalnya penanaman sebesar 1.111 pohon ha-1). Beberapa tanaman ada yang mengalami kerontokan daun yang diawali dengan pembusukan akar akibat serangan Armellaria mellea dan ada pula yang mati pucuk disebabkan jamur Gloesporium anthocephali. Secaraumum, penurunan presentase hidup tanaman disebabkan adanya persaingan dalam memperoleh unsur-unsur hara dalam tanah dan ruang tumbuh serta serangan hama. Pada areal dengan lapisan tanah yang tipis, lebih banyak ditemukan tanaman

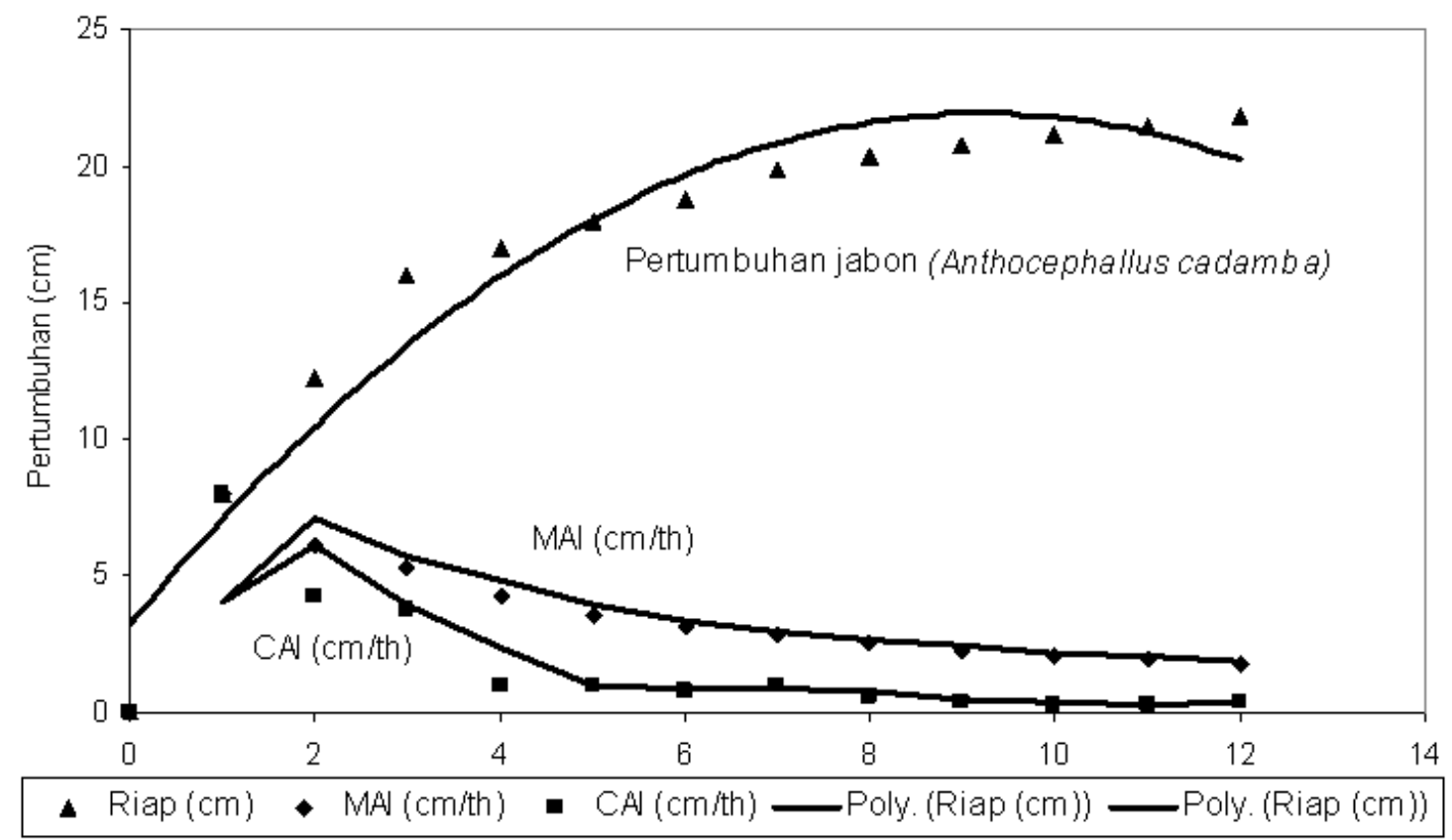

Gambar 1. Grafik pertumbuhan diameter MAI and CAI tanaman jabon 


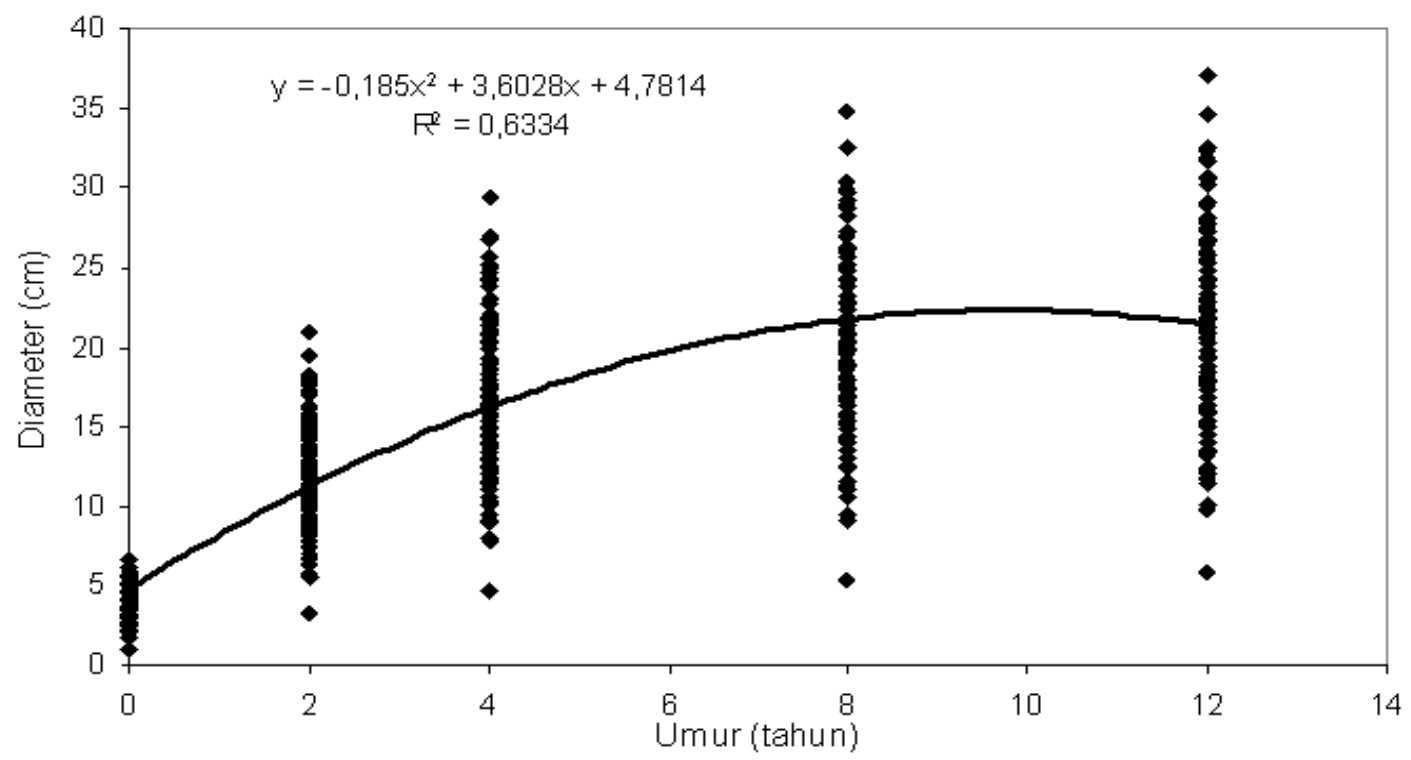

Gambar 2. Model polinomial pertumbuhan jabon

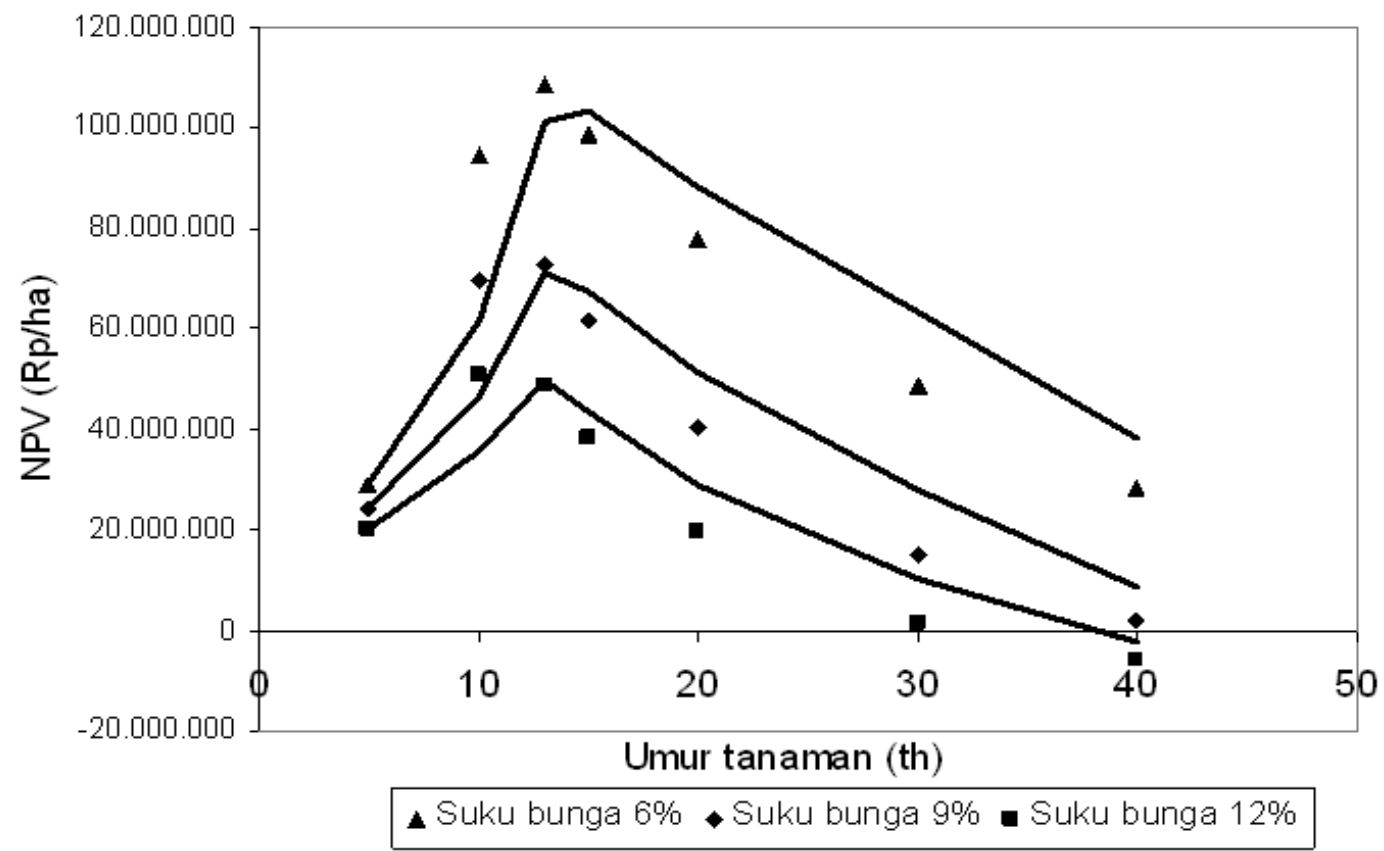

Gambar 3. Perbandingan nilai NPV pada tingkat suku bunga 6,9 dan $12 \%$

kerdil serta kematian, karena keterbatasan unsur hara.

MAI volume total tanaman jabon pada penelitian ini sebesar 19,05 $\mathrm{m}^{3} \mathrm{ha}^{-1} \mathrm{thn}^{-1}$ pada umur 12 tahun. Menurut Manan (1995), riap tanaman jabon sebesar 20-24 $\mathrm{m}^{3}$ ha $^{-1}$ thn-1 dengan rotasi 5-10 tahun. Sedangkan menurut Dephut (1995), tanaman jabon yang berumur 24 tahun dengan kerapatan 160 pohon $\mathrm{ha}^{-1}$, mempunyai diameter rata-rata $32,8 \mathrm{~cm}$; volume $285 \mathrm{~m}^{3}$ ha-1 dan riap MAI 11,9 $\mathrm{m}^{3} \mathrm{ha}^{-1} \mathrm{thn}^{-1}$.
Tanaman jabon merupakan jenis lokal yang masuk dalam kelompok tanaman cepat tumbuh (fast growing species) sehingga mempunyai daur relatif pendek. Model pertumbuhan tanaman jabon pada persamaan polinomial (Brown, 1997; Burkhart, 2003) sebagai berikut:

$y=4,7814+3,6028 x-0,185 x^{2} \quad\left(R^{2}=63,34 \%\right)$

dimana:

y : diameter akhir rata-rata

$\mathrm{x}$ : waktu dalam tahun 
Tabel 2. Prediksi nilai NPV and BCR jabon pada tingkat suku bunga bank 6, 9 dan $12 \%$

\begin{tabular}{cccc}
\hline $\begin{array}{c}\text { Suku bunga bank } \\
\text { (i) }\end{array}$ & Umur tanaman (thn) & NPV $($ Rp ha-1) & BCR \\
\hline & 5 & 28.977 .287 & 4,28 \\
& 10 & 94.509 .143 & 10,08 \\
$6 \%$ & 13 & 108.524 .359 & 10,73 \\
& 15 & 98.616 .821 & 9,51 \\
& 20 & 77.812 .603 & 7,21 \\
& 30 & 48.444 .099 & 4,56 \\
& 40 & 28.156 .884 & 2,82 \\
\hline & 5 & 24.214 .649 & 3,79 \\
& 10 & 69.461 .671 & 7,99 \\
& 13 & 72.792 .689 & 7,95 \\
& 15 & 61.750 .054 & 6,74 \\
& 20 & 40.370 .626 & 4,57 \\
$12 \%$ & 30 & 15.001 .512 & 2,26 \\
& 40 & 1.784 .747 & 1,14 \\
\hline & 5 & 20.182 .986 & 3,36 \\
& 10 & 50.945 .194 & 6,33 \\
& 13 & 48.563 .639 & 5,88 \\
& 15 & 38.120 .555 & 4,76 \\
& 20 & 19.555 .436 & 2,87 \\
& 30 & 1.145 .388 & 1,11 \\
& 40 & -6.156 .918 & 0,43 \\
\hline
\end{tabular}

Berdasarkan model persamaan di atas, dapat diprediksi besaran diameter, tinggi bebas cabang dan volume tanaman jabon di masa datang yang dipergunakanuntukmemprediksipencapaianvolume pada siklus tebangnya. Dengan mempertimbangkan biaya administrasi dan operasional selama daur (pengadaan bibit, penanaman, perawatan), biaya pemanen pada akhir daur serta berasumsi harga kayu jabon sebesar Rp. 1 juta $\mathrm{m}^{-3}$ dengan tingkat suku bunga pinjaman sebesar $9 \%$, maka siklus tebang ekonomis tanaman jabon tercapai pada umur 13 tahun dengan nilai NPV sebesar Rp. 72,79 juta ha-1 dan BCR sebesar 7,95 (Tabel 2).

Menurut Ditjenhut (1980), daur maksimal jabon di Indonesia sekitar 30 tahun dengan riap $24 \mathrm{~m}^{3}$ ha $^{-1}$ thn $^{-1}$. Untuk keperluan kayu lapis, pohon jabon sudah dapat dipanen pada umur 20 tahun atau lebih sedangkan untuk pulp dan kertas sudah dapat dipanen pada umur 10 tahun. Pada perhitungan di atas tanaman jabon masih memberi keuntungan pada umur 40 tahun, yaitu Rp. 1,7 juta ha-1 ${ }^{-1}$ namun kebijakan memperlambat daur tanaman jabon bukanlah keputusan yang tepat, karena tanaman ini sudah memberi keuntungan sangat tinggi pada umur 10 sampai 15 tahun.

Dengan asumsi tingkat suku bunga turun 6 $\%$, maka siklus tebang ekonomis tanaman jabon tercapai pada umur 13 tahun dengan nilai NPV sebesar Rp. 108,52 juta ha-1 dan BCR sebesar 10,73 dan bila tingkat suku bunga naik menjadi 12 $\%$, maka siklus tebang ekonomis tanaman jabon tercapai pada umur 13 tahun juga dengan nilai NPV sebesar Rp.48,56 juta ha-1 dan BCR sebesar 5,88 (Tabel 2).

Makin rendah tingkat suku bunga pinjaman bank maka semakin baik nilai NPV proyek. Seringkali usaha kehutanan yang berjangka waktu panjang kurang menarik bagi investor karena beban suku bunga serta faktor resiko yang tinggi. Oleh karena itu proyek usaha kehutanan sering mendapatkan kucuran dana dengan bunga sangat rendah bahkan mencapai $0 \%$ berupa pinjaman dana reboisasi. Usaha kehutanan disamping mempunyai nilai ekonomi yang cukup baik, juga mengandung unsur perbaikan kualitas lingkungan hidup melalui penyerapan karbon dari udara, pengaturan tata air, mencegah banjir dan erosi serta menjaga kesuburan tanah. 

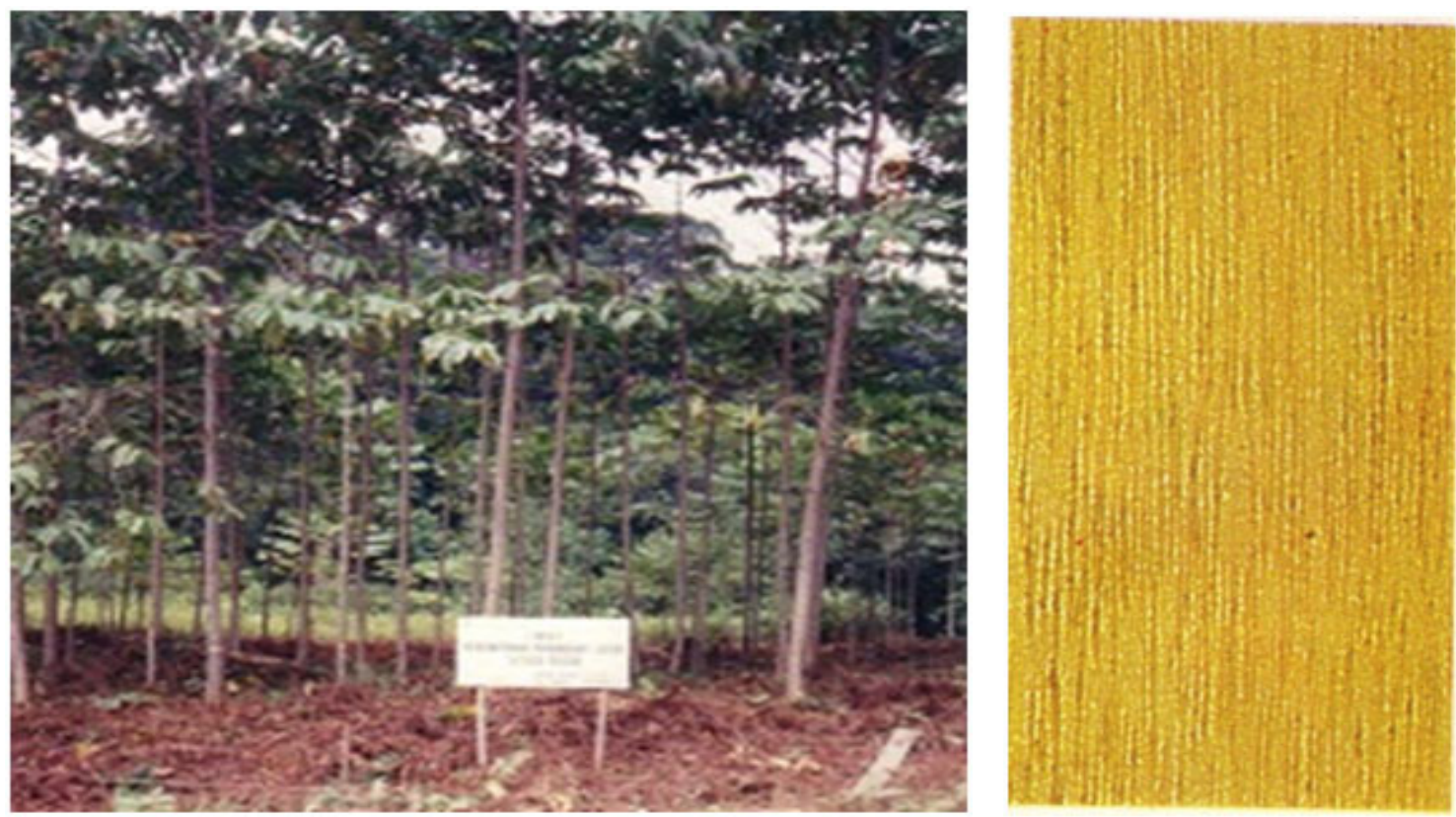

Gambar 4. Tanaman jabon pada kebun penelitian (kiri) dan kayu jabon (kanan)

\section{KESIMPULAN}

Jabon (A. cadamba) adalah jenis komersial lokal yang bersifat intoleran dan dapat tumbuh dengan baik pada areal bekas perladangan, semak belukar dan hutan rawang yang tersebar luas dalam kawasan hutan di Indonesia. Pada umur 12 tahun prosen hidup tanaman jabon mencapai 57,7 \% dengan kerapatan tanaman 641 pohon ha- ${ }^{-1}$ dan MAI sebesar 19,05 $\mathrm{m}^{3}$ ha $^{-1}$ tahun $^{-1}$.

Model pertumbuhan tanaman jabon adalah $\mathrm{y}=$ $4,7814+3,6028 x-0,185 x^{2}\left(R^{2}=63,34 \%\right)$. Pada tingkat suku bunga pinjaman $9 \%$ thn $^{-1}$, tanaman jabon mempunyai siklus tebang ekonomis selama 13 tahun dengan nilai NPV Rp. 72,79 juta ha- ${ }^{-1}$ dan BCR: 7,95 . Apabila tingkat suku bunga pinjaman turun menjadi $6 \%$ atau naik menjadi $12 \%$ thn $^{-1}$ maka siklus tebang ekonomis masih tercapai pada umur 13 tahun dengan nilai NPV-nya masingmasing sebesar Rp. 108,52 juta ha-1 dan Rp. 48,56 juta $\mathrm{ha}^{-1}$. Tanaman jabon dapat dipergunakan untuk kegiatan reboisasi dan penghijauan dalam rangka meningkatkan produktifitas lahan serta layak dikembangkan dalam hutan tanaman industri kelas perusahaan kayu pertukangan dalam skala luas karena permintaan kayunya yang semakin meningkat.

\section{DAFTAR PUSTAKA}

[APHI] Asosiasi Pengusahan Hutan Indonesia, 2010. Perkembangan Produktifitas Hasil Hutan Kayu Indonesia dan Permasalahannya. Badan Litbang Kehutanan, IPB ICC, Bogor, 29 November 2010.

[Balitbanghut]Badan Penelitian dan Pengembangan Kehutanan. 2008. Profil Pusat Penelitian dan Pengembangan Hutan dan Konservasi Alam. Balitbanghut, Departemen Kehutanan, Bogor.

Brown, S. 1997. Estimating biomass change of tropical forest a primer. FAO Forestry Paper No.134. FAO USA.

Burkhart, H. E. 2003. Suggestion for choosing an appropriate level for modelling forest stand. In Amaro A, Reed D, Soares P, editors. Modelling Forest System. CABI Publishing.

[Dephut] Departemen Kehutanan RI. 1989. Atlas Kayu Indonesia. Jilid I dan II. Badan Litbang Dephut, Bogor.

[Dephut] Departemen Kehutanan RI. 1995. Status Penelitian Riap dan Pertumbuhan HTI. Badan Penelitian dan Pengembangan Hutan, Dephut RI, Jakarta.

[Ditjenhut] Direktorat Jenderal Kehutanan. 1980. Pedoman Pembuatan Tanaman. Direktorat Jenderal Kehutanan, Departemen Pertanian, Jakarta.

Gray, C., L. Kadariah and Karlina. 1999. Pengantar Evaluasi Proyek. Edisi Revisi. Lembaga Penerbit Fakultas Ekonomi Universitas Indonesia, Jakarta.

Manan, S. 1995. Riap dan Masa Bera di Hutan Tanaman Industri. Direktorat Jenderal Pengusahaan Hutan, Dephut $\mathrm{RI}$, Jakarta.

Nair, P. K. R. 1993. An Introduction to Agroforestry. Kluwer Academic Publishers. ICRAF. Dordrecht-Boston-London. 